\title{
Assessment of low ABSPI among arsenic exposed and non-exposed populations: A pilot study
}

\author{
Manzurul Haque Khan, Sudipta Sarkar, Nasreen Khan, A.F.M. Sarwar and Sk. Akhtar Ahmad \\ Department of Occupational and Environmental Health, National Institute of Preventive and Social \\ Medicine (NIPSOM), Mohakhali, Dhaka 1212, Bangladesh.e-mail: manhkhan@gmail.com
}

\begin{abstract}
This cross-sectional study was carried out to assess and compare Ankle Brachial Systolic Pressure Index (ABSPI) amongst 120 arsenic exposed and 120 non-exposed populations of Samta village in Bangladesh. Abnormal ABSPI was more prevalent in arsenic exposed $(13.3 \%)$ than in non-exposed (2.5\%) group. The prevalence of abnormal ABSPI for respondents when adjusted for age, sex, BMI, blood pressure status and diabetic status, the prevalence remain significantly different. The findings suggest that those exposed to arsenic have increased chance of having abnormal ABSP and hence increased chance of peripheral arterial disease in Bangladesh.
\end{abstract}

\section{Introduction}

Ankle brachial systolic pressure index (ABSPI) is a non-invasive, reliable test which can detect obstructive peripheral vascular disorder (PAD). Individuals with obstructive arterial disease are known to have abnormal ABSPI ${ }^{1}$. Gangrene is considered a result of compromised blood supply to the part, therefore, those having gangrene most likely had some obstructed disease of the artery/arteries of the lower limbs.

Prolonged consumption of water contains high concentration of arsenic effect on health. The effect is more serious with magnitude of the dose. Chronic arsenic poisoning affects many organs and system in the body including skin, nervous system, liver, peripheral vessels, endocrine system and respiratory organ ${ }^{2-4}$. Exposure to arsenic in occupational settings and environmental contexts similar to that in Bangladesh has been associated with the occurrence of obstructive peripheral arterial disease often culminating in gangrene or spontaneous or surgical amputation(s). Several studies in Bangladesh ${ }^{5-7}$ have had reported the occurrence of gangrene of lower limbs amongst the arsenicosis patients. Arsenic exposed population, besides having traditional risk factors (age, sex, smoking, diabetes, hypertension etc) as in the non exposed population has additional risk factor which is arsenic itself. Arsenic has been found to cause endothelial damage, subsequently leading to atherosclerotic changes and varying degree of arterial obstruction ${ }^{8}$. Moreover, arsenic exposure has been related to development of DM and hypertension which in turn were risk factors for PAD. Based on above observation, it is most likely that arsenic exposed populations in Bangladesh are having high prevalence of PAD, i.e. atherosclerotic obstructive disease and hence ABSPI of $\leq 0.90$, compared to those not exposed to arsenic.

\section{Materials and Methods}

This cross sectional comparative study was carried out during the period of March 2005 to June 2005. Participants of the study were selected into two separate groups which included a group with individuals having excess arsenic exposure ( $>50$ $\mu \mathrm{g} / \mathrm{L}$ ) and arsenicosis, and a reference group comprising of individuals with background level arsenic exposure $(<50 \mu \mathrm{g} / \mathrm{L})$ and no dermatological signs of arsenicosis (melanosis, bilateral palmoplantar keratosis or leucomelanosis). Participants for the study group were selected from amongst previously diagnosed 192 ( $\geq 30$ years of age) arsenicosis patients residing in Samta village of Sharsha Thana under Jessore District of Bangladesh. Participants for the reference group were also selected from same village, but from an area where most of the tube wells did not have arsenic contamination $(<50 \mu \mathrm{g} / \mathrm{L})$ and had been marked green following a previous arsenic screening activity and where no arsenicosis patients have been detected in a previous house to house arsenicosis patient identification activity.

Recruitment of participants for study group was done by household visits based on inclusion and 
exclusion criteria. Inclusion criteria were individuals having evidence of consumed tubewell water whose arsenic content was $>50 \mu \mathrm{g} / \mathrm{L}$, presence of clinical signs of arsenicosis (bilateral palmoplantar keratosis \pm melanosis on the trunk) and age between 30-60 years; exclusion criteria were individuals having evidence of consumed tubewell water whose arsenic content was $<50 \mu \mathrm{g} / \mathrm{L}$, individuals not having the clinical signs of arsenicosis, age $<30$ years or $>60$ years and those who were pregnant or had delivered a baby within the previous 4 months. Informed consent was taken from each individual before starting the study. During the household visits out of 192 previously identified arsenicosis patients contact with 125 patients could be made and ultimately 120 participated in the study. Equal number of participants for the reference group was subsequently selected, also based on inclusion and exclusion criteria [inclusion criteria: individuals who consumed tube well water whose arsenic content was $<50 \mu \mathrm{g} / \mathrm{L}$, individual not having sign of simulating the signs of arsenicosis and age between 30-60 years; exclusion criteria: individuals having evidence of consumed tube well water whose arsenic content was $>50 \mu \mathrm{g} / \mathrm{L}$, individual having sign of simulating the signs of arsenicosis: age $<30$ years or $>60$ years and those who were pregnant or had delivered a baby within the previous 4 months] and informed consent.

Data collection was carried out through face to face interview and examination of the participants using a pre-designed, pre-tested, household interview schedule and checklist. Urine sample of participants were collected for estimation of glucose content, the height and weight of the participant was measured.

Blood pressures were recorded over the right arm according to the protocol recommended by the World Heath Organization. Doppler assisted systolic pressure measurements were taken sequentially on all brachial, posterior tibial, dorsalis pedis arteries ${ }^{10}$. Weight to the respondent was taken by bathroom weighing scale. Height was measured in centimeter using a wooden device, in standing position without foot wear, shoulder blades in contact with the vertical scale ${ }^{11}$. For each participant ABSPI was calculated for each artery of both the lower limbs and the lowest of the 4 ABSPIs was taken as the ABSPI of the participant. Individuals on hypoglycemic agent or having glycosuria were considered as being diabetic.

Data obtained was entered in SPSSWIN 11.5 program and analyzed. Bi-variate and multivariate analyses were carried out using both descriptive and inferential statistics. Both crude and adjusted rates were obtained for both groups, adjustments for the potential confounders (age, sex, smoking status, obesity, hypertension and diabetes) were undertaken. Adjustments were done by direct standardization where the composition of standard population was drawn up by pooling the population distribution in both the groups. The 95\% confidence interval rates were also calculated. And subsequently differences between the rates were evaluated statistically.

\section{Results}

Most of the respondents were 30-49 years of age (80\% in arsenicosis group and $81.7 \%$ in reference group (Table I). The mean age of the respondents of the groups found not to be significantly different $(p<0.05)$. Among respondents in arsenicosis group $59.2 \%$ were male and $40.8 \%$ were female, whereas the reference group was dominated than by female $(59.2 \%)$. The groups were significantly different $(p<0.05)$ in gender. As regards to the type of household of the study participants only a single participant in group A lived in pucca house, while the vast majority both in arsenic exposed $(60 \%)$ and non-exposed group (67.5\%) lived in kachaa house. Moreover the groups were found to be dissimilar $(p>0.05)$ in terms of their dwelling house.

Table I: Socio-demographic characteristics of study participants

\begin{tabular}{|c|c|c|}
\hline \multirow{2}{*}{ Variable } & \multicolumn{2}{|c|}{ Group } \\
\hline & Arsenicosis & Reference \\
\hline Age (years) & $39.97 \pm 9.30$ & $39.34 \pm 8.99$ \\
\hline \multicolumn{3}{|l|}{ Gender } \\
\hline Male & 71 & 49 \\
\hline Female & 49 & 71 \\
\hline \multicolumn{3}{|l|}{ Education } \\
\hline Illiterate & 53 & 63 \\
\hline Primary & 55 & 45 \\
\hline Secondary \& above & 12 & 12 \\
\hline Annual income (Taka) & $22871 \pm 8112$ & $23175 \pm 6183$ \\
\hline \multicolumn{3}{|l|}{$\begin{array}{l}\text { Possession of agricultural } \\
\text { land (bigha) }\end{array}$} \\
\hline Landless & 60 & 59 \\
\hline$<3$ & 52 & 32 \\
\hline $3-25$ & 8 & 29 \\
\hline \multicolumn{3}{|l|}{ Household type } \\
\hline Kachaa & 72 & 81 \\
\hline Semi pucca & 47 & 39 \\
\hline Pucca & 1 & 0 \\
\hline BMI $\left(\mathrm{kg} / \mathrm{m}^{2}\right)$ & $18.64 \pm 3.0$ & $20.02 \pm 3.56$ \\
\hline \multicolumn{3}{|l|}{ Smoking habit } \\
\hline Non-smoker & 96 & 112 \\
\hline Smoker & 24 & 8 \\
\hline
\end{tabular}


Table II: Diabetes mellitus, hypertension and ABSPI status amongst the respondents

\begin{tabular}{|c|c|c|c|}
\hline \multirow{2}{*}{ Variables } & \multicolumn{2}{|c|}{ Group } & \multirow{2}{*}{ Significance } \\
\hline & Arsenicosis & Reference & \\
\hline \multicolumn{4}{|l|}{$\begin{array}{l}\text { Skin manifestations } \\
\text { of arsenicosis }\end{array}$} \\
\hline $\begin{array}{l}\text { Melanosis on the } \\
\text { trunk }\end{array}$ & $120(100 \%)$ & 0 & \\
\hline $\begin{array}{l}\text { Bilateral } \\
\text { palmoplantar } \\
\text { keratosis }\end{array}$ & $50(41.7 \%)$ & 0 & \\
\hline \multicolumn{4}{|l|}{$\begin{array}{l}\text { Presence of urine } \\
\text { glucose }\end{array}$} \\
\hline Yes & 8 & 0 & $\chi_{\mathrm{df}=2}^{2}=$ \\
\hline No & 112 & 120 & $\begin{array}{l}\text { 6.336, } \quad \mathrm{p} \\
\text { value } 0.012^{*}\end{array}$ \\
\hline \multicolumn{4}{|l|}{$\begin{array}{l}\text { Blood pressure } \\
(\mathrm{mmHg})\end{array}$} \\
\hline $\begin{array}{l}\text { Normotensive } \\
(\mathrm{SBP}<120 \& \& \\
\mathrm{DBP}<80)\end{array}$ & 76 & 89 & \\
\hline $\begin{array}{l}\text { Pre hypertensive } \\
\text { (SBP 120-139 or } \\
\text { DBP 80-89) }\end{array}$ & 40 & 27 & $\begin{array}{c}\text { Fisher's } \\
\text { Exact } \\
\text { Test }=3.590\end{array}$ \\
\hline $\begin{array}{l}\text { Hypertensive } \\
(\mathrm{SBP} \geq 140 \text { or } \\
\mathrm{DBP} \geq 90 \text { ) }\end{array}$ & 4 & 4 & $p$ value 0.166 \\
\hline \multicolumn{4}{|l|}{ ABSPI status } \\
\hline $\begin{array}{l}\text { Normal } \\
(0.91-1.30) \\
\text { Abnormal } \\
(\leq 0.90)\end{array}$ & 104 & 117 & $\begin{array}{c}\chi_{\mathrm{df}=1}^{2}=9.659 \\
\mathrm{p} \text { value } \\
0.002^{* *}\end{array}$ \\
\hline
\end{tabular}

*Chi square with Yate's correction; **Significant at 1.96 critical level of significance

All respondents of arsenicosis group had melanosis on the trunk and only $41.7 \%$ had bilateral palmoplantar keratosis (Table II). Edema was present in only $3.3 \%$ of arsenicosis group and $0.8 \%$ in the reference group. None in any of the groups had been suffering from severe anemia, central cyanosis or dehydration and there was no palpable liver, spleen or intra-abdominal mass. None of the participants gave a family history of diabetes and none were being treated with hypoglycemic agents. Among the respondents of arsenicosis group 6.7\% had reducing substance in their urine while none in the reference group had reducing substance in urine. And this observed difference was statistically significant $(p<0.05)$. No participants in either of the groups gave a family history of hypertension and none were being treated with antihypertensive agents. About, $33.3 \%$ and $22.5 \%$ in arsenicosis and reference groups respectively were found to be prehypertensive; while $3.3 \%$ individual in both arsenicosis and reference groups was found to have hypertension. This difference in blood pressure status was found not to be statistically significant $(\mathrm{p}>0.05)$. The proportion of abnormal lower limb ABSPI $(\leq 0.90)$ was higher in arsenicosis group $(13.3 \%)$ than in the reference group $(2.5 \%)$, and this observed difference was found to be statistically significant ( $p>0.05$; Table III).

\section{Discussion}

ABSPI is considered is tool that allows for objectively assessing obstructive arterial disease of lower limb and ABSPI of $\leq 0.90$ has been demonstrated to be both highly sensitive and specific for arteriographically demonstrable obstruction $\geq 50 \%$ of the arterial lumen more in a major leg artery $1,11,12$.

Age, gender, obesity, DM, hypertension all are known risk factors for abnormal ABSPI ${ }^{13}$. Arsenic has been found to have a specific affinity for the vascular bed to be toxic to endothelial cells, subsequently leading to atherosclerotic changes and varying degree of arterial obstruction ${ }^{9}$. Arsenic exposure has also been related to development of $\mathrm{DM}^{14,15}$ and hypertension ${ }^{16,17}$ which in turn were risk factors for lower extremity obstructive arterial disease and thus low ABSPI. In absence of gangrene or symptoms low ABSPI indicates asymptomatic atherosclerotic disease or preclinical condition $^{11,12}$.

An increased risk of atherosclerotic disease of arteries of lower limbs as a result of drinking water containing excess arsenic has been observed in different parts of the globe ${ }^{8,18-20}$. Several studies in Bangladesh $^{6-8}$ have had reported the occurrence of gangrene of lower limbs amongst the arsenicosis patients. Moreover, as preclinical cases of peripheral vascular disease (LEAD) have been found to

Table III: ABSPI and adjusted factors

\begin{tabular}{|c|c|c|c|}
\hline \multirow[t]{2}{*}{ Abnormal ABI status } & \multicolumn{2}{|c|}{ Group } & \multirow[t]{2}{*}{ Significance } \\
\hline & Arsenicosis & Reference & \\
\hline Crude rate $(\%)$ & 13.3 & 2.5 & $\mathrm{SE}(\mathrm{p} 1-\mathrm{p} 2)=.0349, \mathrm{z}$ value $2.92 * *$ \\
\hline Rate $(\%)$ adjusted for age & 13.2 & 2.6 & $\mathrm{SE}(\mathrm{p} 1-\mathrm{p} 2)=.0246, \mathrm{z}$ value $4.29 * *$ \\
\hline Rate $(\%)$ adjusted for age $\&$ gender & 13.4 & 2.5 & $\mathrm{SE}(\mathrm{p} 1-\mathrm{p} 2)=.0247, \mathrm{z}$ value $4.28^{* *}$ \\
\hline Rate $(\%)$ adjusted for BP status & 13.3 & 2.3 & $\mathrm{SE}(\mathrm{p} 1-\mathrm{p} 2)=.0245, \mathrm{z}$ value $=4.32 * *$ \\
\hline $\begin{array}{l}\text { Rate }(\%) \text { adjusted for age, gender, } \\
\text { smoking habit, BMI status, diabetes }{ }^{*} \& \text { BP } \\
\text { status }\end{array}$ & 12.8 & 2.2 & $\mathrm{SE}\left(\mathrm{p}_{1}-\mathrm{p}_{2}\right)=.0240, \mathrm{z}$ value $=4.41 * *$ \\
\hline
\end{tabular}


persist even after decline or cessation of exposure to arsenic ${ }^{19,21}$ cardiovascular consequences could be expected to be persistently higher amongst the arsenic individuals in Bangladesh having LEAD even after provision of safe water options.

The study has revealed a significantly higher prevalence low ABSPI i.e., lower extremity arterial disease among individuals having high arsenic exposure compared to those having background level of exposure. Moreover, those having low ABSPI in addition to having lower extremity arterial disease, most commonly have concomitant atherosclerotic arterial disease in other parts of the arterial system. Thus low ABSPI which is found in lower extremity arterial diseases is a marker of an increased risk of fatal and nonfatal cardiovascular and cerebrovascular disease events and it also associated with a 2-fold increased risk of cardiovascular morbidity and mortality. Thus arsenic exposed population having low ABSPI were not only at risk of progression to gangrene and having amputation, but also to an increased risk of fatal and non-fatal cardiovascular and cerebrovascular disease events.

\section{References}

1. Fowkes FGR. The measurement of atherosclerotic peripheral arterial diseases in epidemiological Surveys. Int J Epidemiol. 1988; 17: 248-54.

2. Khan AW, Ahmed SA, Sayed MH SU, Hadi SA, Khan MH, Jalil MA, Ahmed R, Faruque MH. Arsenic contamination in ground water and its effect on human health with particular reference to Bangladesh. J Prev Soc Med. 1997; 16: 65-73.

3. Kabir MI, Rahaman M, Flora MS, Azad AK Arsenicosis and body mass index (BMI) in a selected area of Bangladesh. J Prev Soc Med. 2001; 20: 6-12.

4. Hadi A, Parveen R. Arsenicosis in Bangladesh: Preventive and socio-economic correlates. Public Health 2004: 118: 559-64.

5. Dhar RK, Biswas BK, Samanta G, Mandal BK, Charkraborti D, Roy S, Jafar A, Islam A, Ara G, Kabir S, Khan AW, Ahmad SA, Hadi SA. Groundwater arsenic calamity in Bangladesh. Curr Sci. 1997; 73: 4859.

6. Ahmad SA, Sayed MHSU, Hadi SA, Faruquee MH, Khan MH, Jalil MA, Ahmed R, Khan AW. Arsenicosis in a village in Bangladesh. Int $\mathrm{J}$ Environ Health Res. 1999; 9: 187-95.

7. Anwar HM, Aktar J, Mostafa KMG, Safiullah S, Tareq SM. Arsenic poisoning in groundwater: Health risk and geochemical sources in Bangladesh. Environ Int. 2002; 27: 597-604.
8. Yu HS, Lee $\mathrm{CH}$, Chen GS. Peripheral vascular diseases resulting from chronic arsenical poisoning. J Dermatol. 2002; 29: 123-30.

9. Rose GA, Blackburn H. Cardiovascular survey methods. Monograph Series No. 56. Geneva, World Health Organization, 1968.

10. Fowkes FGR, Housely E, Riemersama RA, Macintyre CCA, Elizabeth HH, Cawood EHH, Prescott RJ. Smoking, lipids, glucose intolerance and blood pressure as risk factors for peripheral atherosclerosis compared with ischemic heart disease in the Edinburgh Artery study. Am J Epidemiol. 1992; 135: 331-40.

11. Weitz JI, Byrne J, Clagett P, Farkouh ME, Porter JM, Sackett DL, Strandness Jr DE, Taylor LM. Diagnosis and treatment of chronic arterial insufficiency of the lower extremities: A critical review. Circulation 1996; 94: 3026-49.

12. Dieter RS, Chu WW, Pacanowski JP, McBride PE, Tanke TE. The significance of lower extremity peripheral arterial disease: Review. Clin Cardiol. 2002; 25: 3-10.

13. Golledge J. Lower-limb arterial disease. Lancet 1997; 350: 1459-65.

14. Rahaman M, Tondel M, Ahmed SK, Axelson O. Diabetes mellitus associated with arsenic exposure in Bangladesh. Am J Epidemiol. 1998; 148: 198-203.

15. Lai MS, Hsuech YH, Chen CJ, Shyu MP, Chen SY, Kuo TL, Wu MM, Tai TY. Ingested inorganic arsenic and prevalence of diabetes mellitus. Am J Epidemiol. 1994; 139: 484-92.

16. Chen CJ, Hsueh Y, Lai MS, Shyu MP, Chen SY, Wu MM, Kuo TL, Tai TY. Increased prevalence of hypertension and long term arsenic exposure. Hypertension 1995; 25: 53-59.

17. Rahaman M, Tondel M, Ahmed SK, Chowdhury IA, Faruque $\mathrm{MH}$, Axelson O. Hypertension and arsenic exposure in Bangladesh. Hypertension 1999; 33: 7478.

18. Chen CJ. Blackfoot disease. Lancet 1990; 336: 442.

19. Tseng $\mathrm{CH}$, Chong $\mathrm{CK}$, Chen CJ, Tai TY. Dose response relationship between peripheral vascular disease and ingested inorganic arsenic among residents in blackfoot disease endemic villages in Taiwan. Atherosclerosis 1996; 120: 125-33.

20. Wu MM, Kuo TL, Hwang YH, Chen CJ. Dose response relation between arsenic concentrations in well water and mortality from cancers and vascular diseases. Am J Epidemiol. 1989; 130: 1123-32.

21. Tseng CH, Chong CK, Chen CJ. Abnormal peripheral microcirculation in seemingly normal subjects living in blackfoot disease hyperendemic villages Taiwan. Int $\mathrm{J}$ Microcirculation Clin Exp. 1995. 15: 21-27. 